\title{
The initial research on the compressive strength of mortar when using bottom ash from thermal power plants to replace natural sand in construction
}

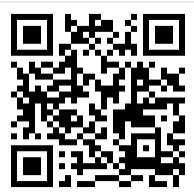

\author{
Hung Van Nguyen *, Son Truong Bui, Hai Huu Phung, Ha Ngoc Thi Pham \\ Faculty of Geosciences and Geoengineering, Hanoi University of Mining and Geology, Vietnam
}

\section{ARTICLE INFO \\ Article history: \\ Received 21 ${ }^{\text {st }}$ Feb. 2020 \\ Revised 23rd May 2020 \\ Accepted 30thJune 2020}

\section{Keywords:}

An Khanh TPP,

Bottom ash,

Cao Ngan TPP,

Compressive strength,

Mortar,

Replacement materials.

\section{ABSTRACT}

The paper presents the compressive strength of mortar samples when replacing natural sand by bottom ash of An Khanh and Cao Ngan thermal power plants (TPPs) in Thai Nguyen province. Experimental research is the main method applied in this research. Research results show that replacing natural sand by bottom ash in the two TPPs, the compressive strength of samples reached the required mortar's strength. The compressive strength of the mortar sample replaced all-natural sand, particularly for masonry mortar and plastering mortar, is $10.9 \mathrm{MPa}$ and 16.4 MPa respectively for An Khánh TTP, and 12.7 MPa and 12.6 MPa for Cao Ngan TTP, while the compressive strength of the motar used all natural sand, reached 13.2 MPa and 8.6 MPa.

Copyright (C) 2020 Hanoi University of Mining and Geology. All rights reserved.

\section{Introduction}

Today, bottom ash not only can be used to produce unburnt bricks, but also used as an aggregate component in concrete (Dinh Quoc Dan and etc, 2019; Ho Ngoc Hung, 2018; Nguyen Thi $\mathrm{Nu}$ et al., 2020).

Basing on the surveys, most of the bottom ash from the Cao Ngan thermal power plant (thermal power plant - TPP) is utilized for the production of unburnt bricks while that from An Khanh (TPP) still faces many difficulties.

${ }^{*}$ Corresponding author E-mail:nguyenvanhung.dcct@humg.edu.vn DOI: 10.46326/JMES.2020.61(3).02
In addition, the construction of infrastructure requires a huge source of materials. However, common materials that were used in construction, including sand, cobble, gravel, or macadam, are decreasing. Therefore, the study of using alternative materials from natural resources such as sand, cobble, gravel is an urgent issue to cut down construction costs as well as to promote sustainable development and environmental protection. Moreover, other purpose of using alternative materials such as bottom ash is to reduce the negative environmental iMPacts on the locality. The principle of these alternative materials is to ensure that it is locally available. So, to create a breakthrough in the field of new materials, 
research on using bottom ash to replace natural materials could create new perspects in the building materials field. One of the main parameters of construction mortar in this study is compressive strength. The composition of mortar in this study is bottom ash from sand, water, and cement of An Khanh and Cao Ngan TTPs

\section{Dumping sites of Cao Ngan and An Khanh TPP}

\subsection{The dumping site of Cao Ngan TPP}

Cao Ngan TPP is built on the Thai Nguyen TPP, about $2 \mathrm{~km}$ northwest of the center of Thai Nguyen city, surrounded by Quan Trieu and Quang Vinh wards, Thai Nguyen city and Cao Ngan commune, Dong Hy district. Cao Ngan TPP's area is 15 hectares, and the part adjacent to the Cau River has a length of 388.9 meters. The TPP has a capacity of $100 \mathrm{MW}$, with an annual output of 600 million $\mathrm{kWh}$ and a total investment of 123.9 million USD (Bui Truong Son, 2019). It is estimated that Cao Ngan TPP generates yearly about 200,000 tons of bottom ash.

The dumping site area has a deep terrain. In May 2019, the ash of the plant was dumped about $700 \mathrm{~m}$ away from the road, about $1 \div 2 \mathrm{~m}$ high. Ash from the TPP is sprayed with water to reduce dirt and negative iMPacts on the environment.

The current status of the dumping site of Cao Ngan TPP is shown in Figure 1.

\subsection{An Khanh TPP dumping sites}

An Khanh TPP is located in An Khanh No. 1 industrial zone, in An Khanh commune, Dai Tu district, Thai Nguyen province. The total area of this TPP is 35.5 hectares, and the dumping site is about 17.8 hectares. The TPP is roughly $0.5 \mathrm{~km}$ from the coal mining area of Khanh Hoa coal mine to the East and about $6 \mathrm{~km}$ from the center of Thai Nguyen city to the Southeast.

In coMParison with Cao Ngan TPP, An Khanh TPP fails to offer solutions to consume the bottom ash. At the same time of the survey conducted, the factory's disposal area is from $10 \div 18 \mathrm{~m}$ high and approximately 10 hectare wide. There are between $20 \div 25$ trucks carrying ash from the factory to the dump every day. Although An Khanh Thermal Power CoMPany has expanded its disposal area, the issue of ash storage will not be resolved in the near future.

The current status of the dumping site of An Khanh TPP is shown in Figure 2.

\section{Composition and properties of materials in the research}

\subsection{Materials}

In this study, the materials used are bottom ash from An Khanh and Cao Ngan TPPs, natural sand, cement, and water. Vicem But Son PCB40 cement is also used in the study.

The specifications of the above materials are shown in Tables 1, 2

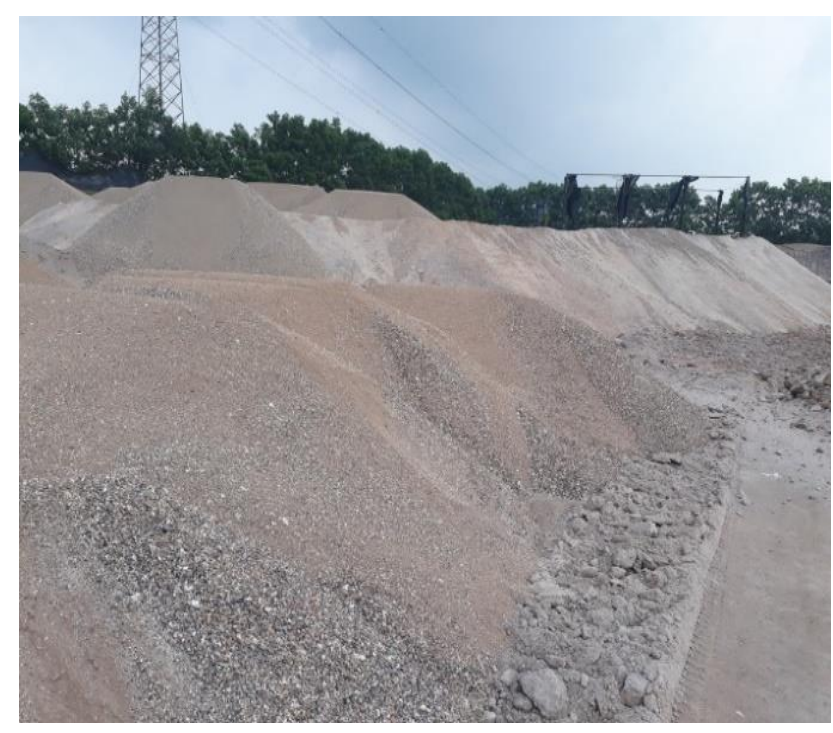

Figure 1. The dumping site of Cao Ngan TPP.

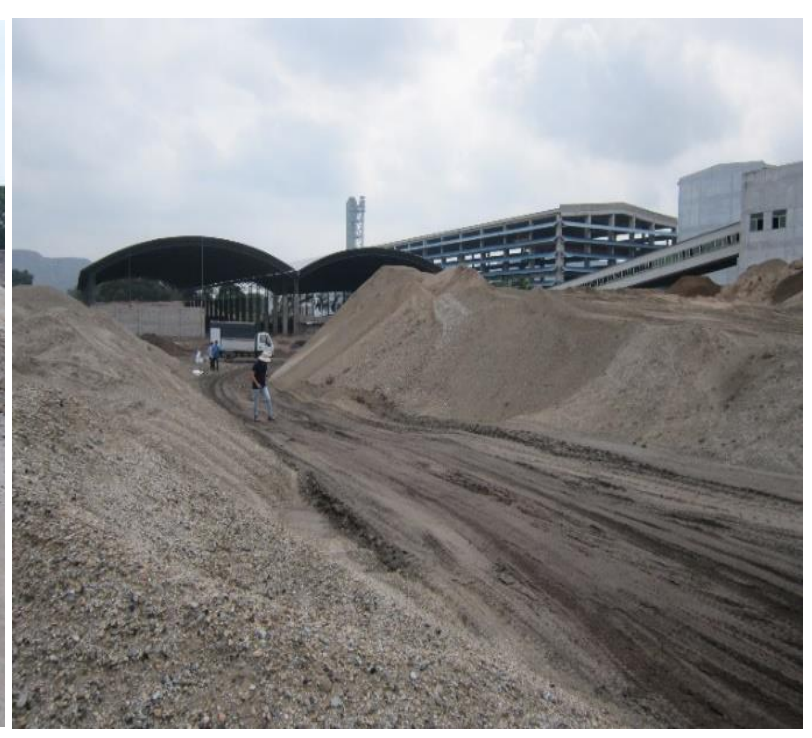

Figure 2. The dumping site of An Khanh TPP. 
Table 1. Technical specifications of materials used in the study.

\begin{tabular}{|c|c|c|}
\hline No. & Material & The technical specifications of materials \\
\hline 1 & Water & - Following the TCVN 4506: 2012 standard \\
\hline 2 & Fine sand & $\begin{array}{l}\text { - Following the TCVN 7570: } 2006 \text { standard. } \\
\text { - Particle composition is within the allowed range. } \\
\text { - Units weight (Sand pouring method): } 1,42 \mathrm{~g} / \mathrm{cm}^{3} \text {. } \\
\text { - Fineness modulus ML }=1,6 \text {. }\end{array}$ \\
\hline 3 & Coarse sand & $\begin{array}{l}- \text { Following the TCVN 7570: } 2006 \text { standard } \\
\text { - Particle composition is within the allowed range } \\
\text { - Units weight (Sand pouring method): } 1,61 \mathrm{~g} / \mathrm{cm}^{3} \text {. } \\
\text { - Fineness modulus ML = 2,96 }\end{array}$ \\
\hline \multirow{2}{*}{4} & \multirow{2}{*}{ Bottom ash } & $\begin{array}{l}\text { - Bottom ash in masonry mortar (An Khanh TPP): } \\
\text { + Units weight (Sand pouring method): } 1,29 \mathrm{~g} / \mathrm{cm}^{3} \text {; } \\
\text { + Fineness modulus ML = 2,96; } \\
\text { - Bottom ash in plastering mortar (An Khanh TPP): } \\
\text { + Units weight (Sand pouring method): } 1,24 \mathrm{~g} / \mathrm{cm}^{3} \text {; } \\
\text { + Fineness modulus 1,6; } \\
\text { + Loss of ignition: } 3,99 \% ;\end{array}$ \\
\hline & & $\begin{array}{l}\text { - Bottom ash in masonry mortar (Cao Ngan TPP): } \\
\text { + Units weight (Sand pouring method): } 1,19 \mathrm{~g} / \mathrm{cm}^{3} \text {; } \\
\text { + Fineness modulus ML }=2,96 \text {. } \\
\text { - Bottom ash in plastering mortar (Cao Ngan TPP): } \\
\text { + Units weight (Sand pouring method): } 1,23 \mathrm{~g} / \mathrm{cm}^{3} \text {; } \\
\text { + Fineness modulus ML = } 1,6 ; \\
\text { + Loss of ignition: } 12,7 \% .\end{array}$ \\
\hline
\end{tabular}

Table 2. Composition of $1 \mathrm{~m}^{3}$ fresh masonry mortar.

\begin{tabular}{|c|c|c|c|c|c|c|}
\hline No. & Sample & Bottom ash $(\mathrm{kg})$ & Coarse sand $(\mathrm{kg})$ & Water $(\mathrm{l})$ & Cement $\mathrm{k}(\mathrm{g})$ & Note \\
\hline 1 & AK1 & 1267 & 0 & 304 & 329 & An Khanh \\
\hline 2 & AK2 & 1273 & 0 & 306 & 382 & An Khanh \\
\hline 3 & AK3 & 1307 & 0 & 376 & 418 & An Khanh \\
\hline 4 & AK4 & 1080 & 345 & 318 & 345 & An Khanh \\
\hline 5 & AK5 & 856 & 690 & 331 & 359 & An Khanh \\
\hline 6 & AK6 & 574 & 1065 & 334 & 362 & An Khanh \\
\hline 7 & CN1 & 1228 & 0 & 340 & 340 & Cao Ngan \\
\hline 8 & CN2 & 1241 & 0 & 396 & 396 & Cao Ngan \\
\hline 9 & CN3 & 1247 & 0 & 425 & 425 & Cao Ngan \\
\hline 10 & CN4 & 1029 & 345 & 350 & 350 & Cao Ngan \\
\hline 11 & CN5 & 766 & 687 & 398 & 357 & Cao Ngan \\
\hline 12 & CN6 & 530 & 1059 & 333 & 361 & Cao Ngan \\
\hline 13 & CV & 0 & 1829 & 347 & 376 & Coarse sand \\
\hline
\end{tabular}

Since the particle size distribution of bottom ash from the two TTPs is not entirely located in zone 1 (corresponding to sand used in masonry mortar), zone 2 (corresponding to sand used in plastering mortar) according to the TCVN 1770: 1986 - Sand for construction - Technical requirements. Thus, these materials must be changed the gradation before using it. Grading of masonry sand, plastering sand, and bottom ash of An Khanh and Cao Ngan TPPs is shown in Figure 3.

\subsection{Sample preparation}

The study is carried out at the geotechnical laboratory at the Hanoi University of Mining and 
Geology and the laboratory of Vietnam Institute for Building materials (International standard ISO/IEC 17025:2005, Lab. Code VILASS 003).

\section{Designing the mortar composition}

The table lookup method is combined with the experiment.

The mortar composition for a ingot sample in this study is designed according to Tables 2 and 3.

\section{Sample preparation}

(TCVN 3121: 2003 - Mortar for masonry Test methods)

Ingredients of gradients are taken in line with
Tables 2 and 3. Put all ingredients in a pan, use a mixture to mix.

Put the mortar mixture on a prismatic metal mold. The mold consists of 3 coMPartments, removable for each bar. The size of each coMPartment of the mold is: length $160 \mathrm{~mm}+0.8$ $\mathrm{mm}$, width $40 \mathrm{~mm}+0.2 \mathrm{~mm}$, and height $40 \mathrm{~mm}+$ $0.1 \mathrm{~mm}$.

The mortar mixture is coMPacted with a pestle. The sample dress is made from nonabsorbent material with a cross-section of squareshaped with edges by $12 \mathrm{~mm} \pm 1 \mathrm{~mm}$, and the weight is $50 \mathrm{~g}+1 \mathrm{~g}$.

Particle size dis. graph

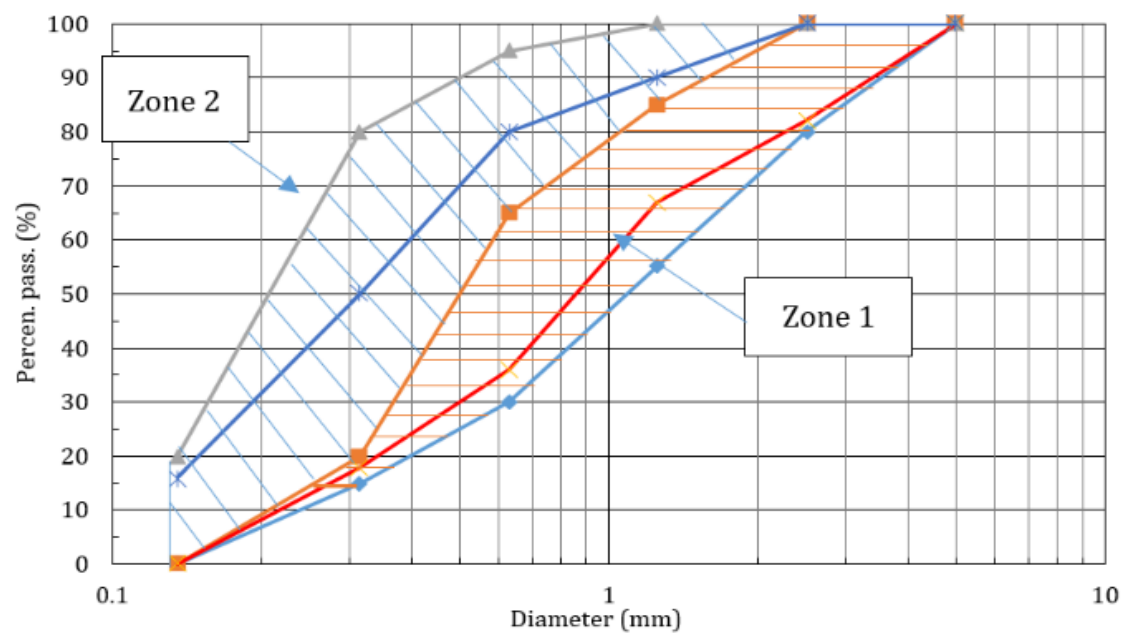

Figure 3. The particle size distribution of bottom ash and sand in the study.

Zone 1 - material used in masonry mortar (bottom ash of An Khanh and Cao Ngan TPPS and natural sand for masonry mortar); Zone 2 - material used in plastering mortar(bottom ash of An Khanh and Cao Ngan TPPS and natural sand for plastering mortar).

Table 3. Composition of $1 \mathrm{~m}^{3}$ fresh plastering mortar.

\begin{tabular}{|c|c|c|c|c|c|c|}
\hline No. & Sample & Bottom ash $(\mathrm{kg})$ & Fine sand $(\mathrm{kg})$ & Water $(\mathrm{l})$ & Cement $(\mathrm{kg})$ & Note \\
\hline 1 & AK7 & 1160 & 0 & 359 & 311 & An Khanh \\
\hline 2 & AK8 & 1123 & 0 & 371 & 346 & An Khanh \\
\hline 3 & AK9 & 1099 & 0 & 408 & 353 & An Khanh \\
\hline 4 & AK10 & 923 & 271 & 362 & 314 & An Khanh \\
\hline 5 & AK11 & 699 & 535 & 357 & 309 & An Khanh \\
\hline 6 & AK12 & 460 & 815 & 362 & 313 & An Khanh \\
\hline 7 & CN7 & 1160 & 0 & 359 & 311 & Cao Ngan \\
\hline 8 & CN8 & 1123 & 0 & 371 & 346 & Cao Ngan \\
\hline 9 & CN9 & 1126 & 0 & 372 & 362 & Cao Ngan \\
\hline 10 & CN10 & 941 & 265 & 356 & 308 & Cao Ngan \\
\hline 11 & CN11 & 699 & 535 & 357 & 309 & Cao Ngan \\
\hline 12 & CN12 & 478 & 846 & 300 & 325 & Cao Ngan \\
\hline 13 & CM & 0 & 1389 & 298 & 323 & Fine sand \\
\hline
\end{tabular}


Pouring the mortar mixture into the mold into 2 layers. Use a ram to dress 25 times for each layer. Leveling the mouth of the sample with a knife, and then covering the glass above the sample, and service the sample in a maintenance bin. After 2 days, remove the sample from the mold and place them in a sample mat for the specified time (Figure 4).

To determine the compress strength of the mortar, we need 3 samples for each composition.

\subsection{Methods}

The compress strength of the mortar sample is determined as the standard TCVN 3121: 2003 Mortar for masonry - Test methods;

After curing, samples are brought to determine the compress strength. Perform sample compression with an increased rate of loading from $100 \div 300 \mathrm{~N} / \mathrm{s}$ until the samples are destroyed. Note that placing the sample in the compressor to make sure the two faces of the sample are smooth sides (Figure 5).

The compressive strength $R_{n}$ of each test piece is the average of the three compressed samples. It is calculated by the formula:

$$
R_{n}=P_{n} / A
$$

Where: $P_{n}$ : Maximum compression force, $N$; $A$ : Sample area, $\mathrm{mm}^{2}$.

\section{Test results and discussions}

\subsection{Test results}

Some properties of the fresh mortar such as consistence by flow table (Figure 5), bulk density are shown in Table 4.

According to the test result, when using the bottom ash in mortar, the bulk density of the mortar mixture decreases. Specifically, when using bottom ash replacing natural sand, the bulk density of mortar mixture decreased from $3.7 \div 12.4 \%$ for masonry mortar and from $1.8 \div 8.3 \%$ for plastering mortar.

Figure 5 shows the consistence by flow table of fresh mortar in laboratory.

The results of compression tests are presented in Figure 6.

\subsection{Discussions}

As mentioned in the test results, it can be seen

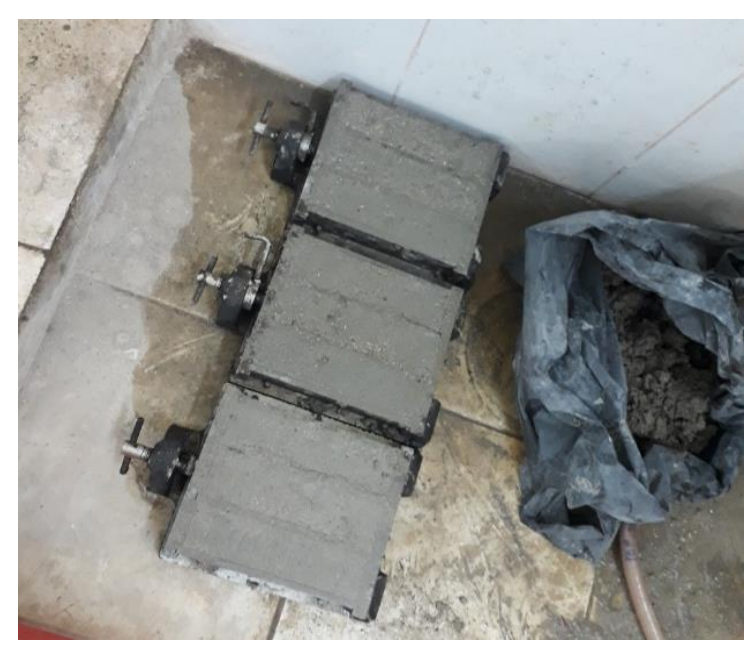

Figure 3. Sample preparation.

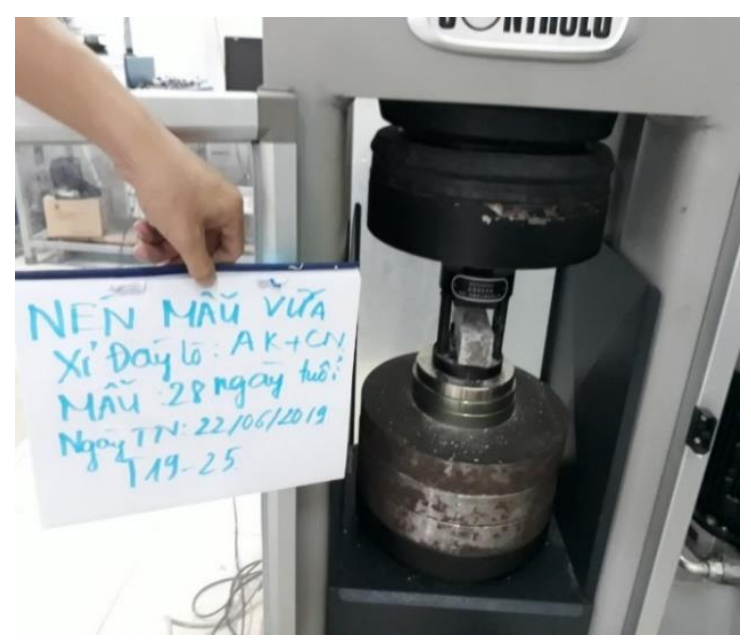

Figure 4. Compressing the sample in the laboratory.

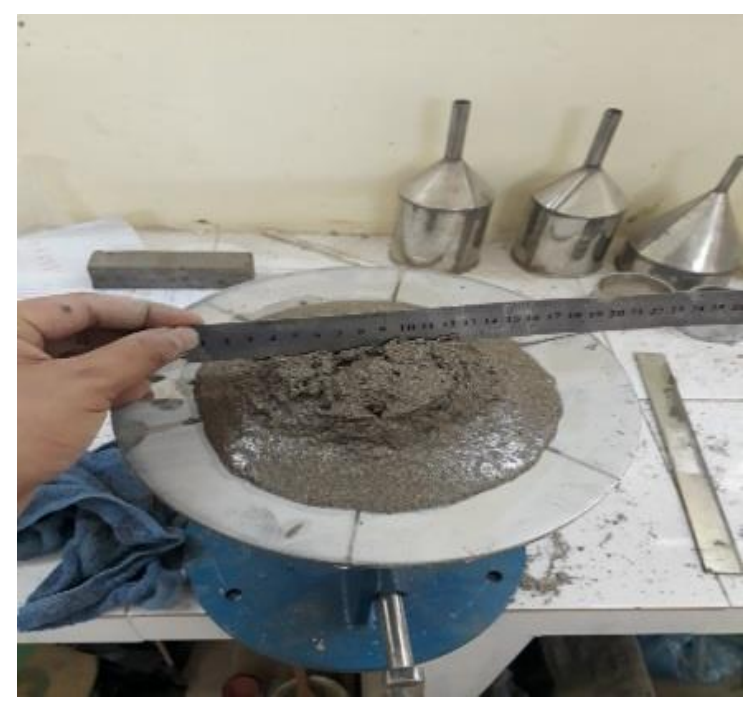

Figure 5. Determining the consistence by flow table of fresh mortar in the laboratory. 
Table 4. Some properties of the fresh mortar in the study.

\begin{tabular}{|c|c|c|c|c|c|c|c|}
\hline TT & Sample No. & Consistence, $\mathrm{mm}$ & $\begin{array}{c}\text { Bulk density, } \\
\mathrm{g} / \mathrm{cm}^{3}\end{array}$ & TT & Sample No. & $\begin{array}{c}\text { Consistence, } \\
\mathrm{mm}\end{array}$ & $\begin{array}{c}\text { Bulk density, } \\
\mathrm{g} / \mathrm{cm}^{3}\end{array}$ \\
\hline 1 & AK1 & 170 & 1.90 & 14 & AK7 & 180 & 1.83 \\
\hline 2 & AK2 & 165 & 1.91 & 15 & AK8 & 175 & 1.84 \\
\hline 3 & AK3 & 200 & 1.96 & 16 & AK9 & 205 & 1.86 \\
\hline 4 & AK4 & 170 & 1.99 & 17 & AK10 & 175 & 1.87 \\
\hline 5 & AK5 & 175 & 2.07 & 18 & AK11 & 180 & 1.90 \\
\hline 6 & AK6 & 185 & 2.09 & 19 & AK12 & 185 & 1.95 \\
\hline 7 & CN1 & 175 & 1.96 & 20 & CN7 & 190 & 1.83 \\
\hline 8 & CN2 & 170 & 1.98 & 21 & CN8 & 180 & 1.84 \\
\hline 9 & CN3 & 165 & 1.99 & 22 & CN9 & 180 & 1.86 \\
\hline 10 & CN4 & 175 & 2.02 & 23 & CN10 & 175 & 1.87 \\
\hline 11 & CN5 & 180 & 2.06 & 24 & CN11 & 175 & 1.90 \\
\hline 12 & CN6 & 185 & 2.08 & 25 & CN12 & 180 & 1.95 \\
\hline 13 & CV & 195 & 2.17 & 26 & CM & 195 & 2.01 \\
\hline
\end{tabular}
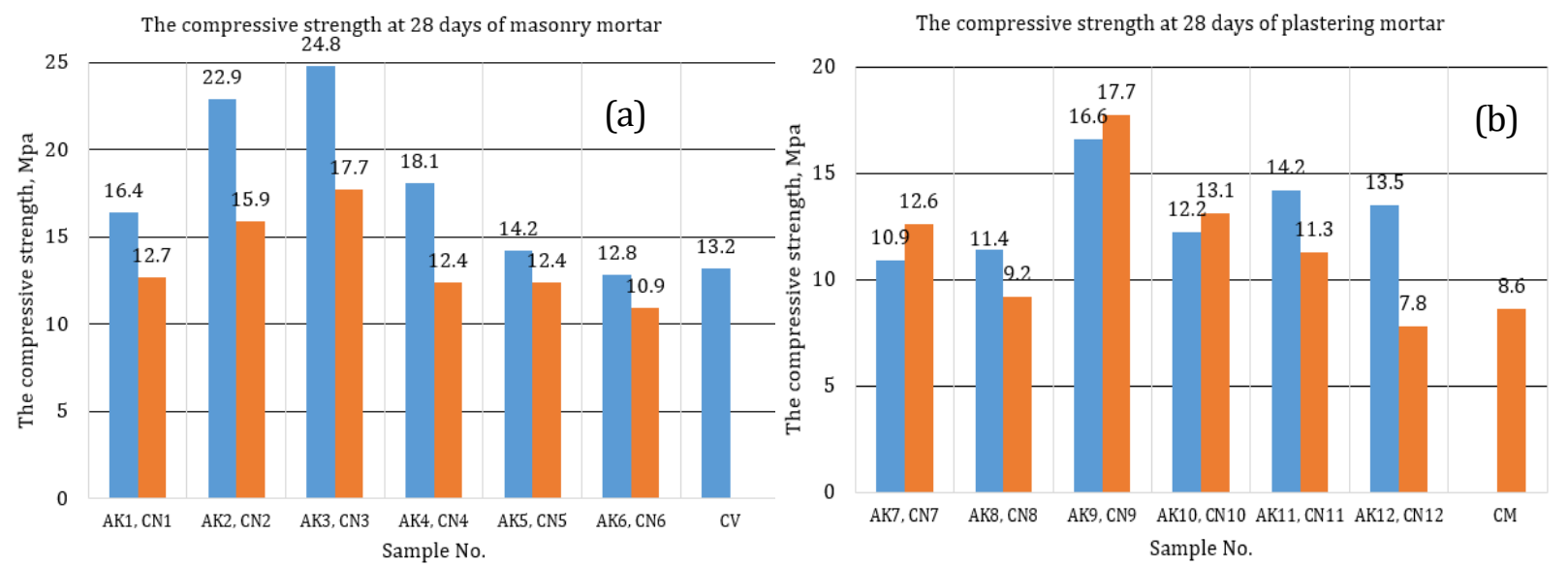

Figure 6. The compressive test results at 28 days of mortar in the study.

(a) Masonry mortar; (b) Plastering mortar.

that the samples using the bottom ash of these TPPs as masonry and plastering mortar have a variety of compressive strength.

The compressive strength of mortar samples, with regard to the bottom ask of An Khanh TTP, is much higher than the initially required strength. The compressive strength of the mortar sample, particularly masonry mortar, using $100 \%$ of coarse sand, is $13.2 \mathrm{MPa}$. In contrast, the mortar uses bottom ash to partially replace or replace all natural sand, the compressive strength varies from 12.8 to $24.8 \mathrm{MPa}$. Especially, samples using bottom ash with the amount of cement increased by $20 \%$; meanwhile, the compressive strength of AK1 is $24.8 \mathrm{MPa}$ (nearly double that of with a sample using coarse sand). The compressive strength of the sample using $100 \%$ natural sand, regarding plastering mortar, reaches $8.6 \mathrm{MPa}$, while the compressive strength of the mortar using all or part of the bottom ash ranges from 10.9 to $16.6 \mathrm{MPa}$. The highest compressive strength of bottom ash in An Khanh TPP for plastering mortar is also the highest among the samples with an increase of $20 \%$ in cement coMPared to AK7.

In relation to Cao Ngan TPP, the compressive strength of some masonry and plastering mortar samples does not share the similarity with that of natural sand. Specifically, CV samples have a compressive strength of $13.2 \mathrm{MPa}$, while samples CN1, CN4, CN5, CN6 have compressive strength ranging from 10.9 to $12.4 \mathrm{MPa}$. However, the compressive strength of these samples still meets the requirements (at least $10 \mathrm{MPa}$ ). To be used as 
a mortar, the compressive strength of samples with cement content increased by $20 \%$ coMPared to $\mathrm{CN} 1$ still reached the highest value $(17.7 \mathrm{MPa})$. In terms of plastering, CN9 has the highest intensity, reaching 17.7 $\mathrm{MPa}$.

The compress strength of masonry mortar is higher than that of the plaster because of the larger coarse grain content. In addition, the compress strength mortar at An Khanh TTP is higher than that of Cao Ngan TTP due to its less burning component $(3.99 \%$ and $12.7 \%$ respectively). Because of the difference of particle shape when replacing river sand by bottom ash, the compress strength can be changed. CoMParing to some lastest researches, these study results are completely reasonable. For example, the project code TD 16-17, Le Van Quang, (2019) illustrated that relatively $95 \%$ of thermal fly ash can be used in the fabricate materials. In this study, bottom ash from two TTPs can replace all natural sand in a mortar with the rational composition.

\section{Conclusions}

According to the research results, some conclusions can be drawn as follows:

- The compressive strength of the samples when using bottom ash at the both An Khanh and Cao Ngan TPPs for masonry mortar is higher than that of plastering mortar.

- The compressive strength of the bottom ash sample from An Khanh TPP is higher than that of bottom ash from Cao Ngan TPP for both masonry and plastering purposes.

- The compressive strength for both purposes of masonry and plastering mortars in both TTPs are the highest out of samples with a $20 \%$ cement increase.

It can be seen that, when the percentage of cement in mortar increases, the compress strength also shares the same trend. But growing the amount of cement could result in the rise of mortar cost. So, the proportion of the mortar of AK1, CN1, AK7, CN7 can be optimum. It is not only responsive in terms of compress strength but also economically responsive.

\section{Acknowledgments}

We would like to express my sincere gratitude to Hanoi University of Mining and Geology for financial backing this research under the project No. T19-25. We also pay a deep sense of gratitude to Bui Truong Son, Nguyen Thi Nu, and Phung Huu Hai for their encouraging and valuable guidance to carry on the experiments in this study.

\section{References}

Bui Truong Son, Nguyen Thi Nu, Nguyen Van Hung, Pham Thi Ngoc Ha, Phung Huu Hai, Bui Van Binh, Nguyen Ngoc Dung, (2019). Final report of the provincial scientific and technological research project: Research on using the ash of Thai Nguyen TPP in building roads for sustainable development and environmental protection. Code DTCN.25/ 2017.

Dinh Quoc Dan, Doan The Tuong, Do Ngoc Son, (2019). Using the fly ash from the thermal power plant as a grade material. Construction Science and Technology - 1/2019.

Ho Ngoc Hung, (2018). Researching technology to produce useful materials from fly ash in Vinh Tan thermal power plant - Binh Thuan. Code VAST03.02-17/18.

Le Van Quang, (2018). Final report of Ministry of the construction research project: Research using thermoelectric fly ash to fabricate materials and construction solutions to prevent pollution and harden pollution for industrial solid waste dumps Code TD 16-1.

TCVN 1770: 1986 - Sand for construction Technical requirements.

TCVN 3121: 2003 - Mortar for masonry - Test methods. 